\title{
O papel da tecnologia da informação na gestão do conhecimento
}

\author{
Adroaldo Guimarães Rossetti \\ Doutorando em engenharia e gestão do conhecimento - EGC/UFSC \\ E-mail: adroaldo@cnpat.embrapa.br
}

Aran Bey Tcholakian Morales

Doutor em pesquisa operacional e sistemas, Universidade Federal de Santa Catarina (UFSC).

E-mail: aran@stela.ufsc.br

\section{Resumo}

Embora a Gestão do Conhecimento (GC) seja função comum nas organizações, muitas não têm visão clara de como incorporá-la e transformá-la em vantagem competitiva. A escassez de estudos comprovando que a GC faz diferença no desempenho organizacional, e a cultura, talvez sejam os fatores mais influentes na promoção ou inibição de práticas de GC. Há empresas que usam ferramentas de Tecnologia da Informação (TI) como fator de competitividade, confundindo-as com GC. Outras acreditam que a TI sozinha possa servir para gerenciar o conhecimento, o que é um equívoco. A razão disso pode estar no surgimento da TI antes da GC, ou na escassez da literatura abordando a função da TI na GC. Daí a falta de clara distinção entre $\mathrm{TI}$ e GC que vise à interação adequada entre ambas. O papel principal da TI é dar suporte à GC, ampliando o alcance e acelerando a velocidade de transferência do conhecimento. É identificar, desenvolver e implantar tecnologias que apóiem a comunicação empresarial, o compartilhamento e a gestão dos ativos de conhecimento. A TI desempenha papel de infra-estrutura, a GC envolve aspectos humanos e gerenciais. Este artigo discute a interação entre TI e GC como instrumentos de gestão estratégica e desempenho organizacional.

Palavras-chave

Gestão do conhecimento. Tecnologia da informação. Desempenho organizacional. Estratégia em gestão do conhecimento. Ambiente de compartilhamento.

\section{The role of information technology in knowledge management}

\begin{abstract}
Although Knowledge Management (KM) has ordinary function in organizations, many of them still do not have a clear vision on how to incorporate and change it into competitive advantage. The lack of empirical studies that assess the difference of KM in organizational performance, and culture, are perhaps the major factors in GC practical promotion or inhibition. Some companies use Information Technology (IT) tools as competitiveness factor, misunderstanding it as GC. Others believe that IT alone can be used for managing knowledge - it is a mistake. The reason for this can be the arising of IT before KM, or the scarcity of literature dealing with IT function in GC. So, there is a lack of clear distinction between IT and KM concerning the appropriate interaction between them. The main IT role is to give support to KM, enlarging its scope and speeding up knowledge transference, as well as to identify, develop and implant technologies that support the enterprise communication, the sharing and management of knowledge assets. IT plays an infrastructure role; the KM involves human and managerial aspects. This paper discusses the interaction between IT and KM as tools that support strategic management and organizational performance.
\end{abstract}

\section{Keywords}

Knowledge management. Information technology. Organisational performance. Strategy in knowledge management. Sharing environment.

\section{INTRODUÇÃO}

A evolução tecnológica que envolve o mundo, as organizações e as pessoas atinge praticamente todas as atividades e favorece a veiculação livre e rápida de grande volume de informações por diversos meios, principalmente pela Internet. A rapidez de evolução nessa área ocorreu, segundo Schreiber et al. (2002), em vista da necessidade de tecnologias padronizadas e eficientes na melhoria da qualidade dos processos e de modelos práticos e ágeis. Esses autores destacam dois elementos-chave para dirigir este processo:

a) o rápido crescimento da rede mundial de computadores "world wide web (www)", que estabeleceu uma infraestrutura de compartilhamento do conhecimento;

b) a identificação do conhecimento como fator chave de produção, além do trabalho e do capital.

Sob a ótica do valor do conhecimento e na busca de orientar indivíduos e empresas a conquistar espaços nas instituições e nos mercados, muitas pesquisas têm sido conduzidas. Praticamente todas essas pesquisas enfatizam a informação e o conhecimento como sendo hoje os bens de maior valor. Nesse contexto, a nova economia, chamada economia do conhecimento, é fundamentada na capacidade intelectual para gerar riquezas. Apoiados nesse raciocínio, vários autores, entre os quais Mukherji e Mukherji (2003), têm levado pessoas e organizações a refletir sobre que estratégias adotar para implantar modelos gerenciais baseados em conhecimento.

A tecnologia da informação (TI), que é gerada e explicitada devido ao conhecimento das pessoas, tem sido, ao longo do tempo, cada vez mais intensamente empregada como instrumento para os mais diversos fins. É utilizada por indivíduos e organizações, para acompanhar a velocidade com que as transformações vêm ocorrendo no mundo; para aumentar a produção, melhorar a qualidade dos produtos; como suporte à análise de mercados; para tornar ágil e eficaz a interação com mercados, com clientes e até com competidores. É usada como ferramenta de comunicação e gestão empresarial, de modo que organizações e pessoas se mantenham operantes e competitivas nos mercados em 
que atuam. Em face disso, além de sua rápida evolução, é cada vez mais intensa a percepção de que a tecnologia de informação e comunicação não pode ser dissociada de qualquer atividade, como importante instrumento de apoio à incorporação do conhecimento como o principal agregador de valor aos produtos, processos e serviços entregues pelas organizações aos seus clientes. A figura 1, que lembra a visão piramidal da evolução dos sistemas de informação referida por Martin (1982), Martin e Leben (1989), adaptada e apresentada por Pacheco e Kern (2003), com base no trabalho de Pant e Hsu (1995), dá uma idéia de como a tecnologia da informação e comunicação evoluiu nas organizações.

Nota-se, pois, ao longo do tempo, conforme O'Brien (2004), considerável expansão das funções dos sistemas de informação computadorizados, causando impacto a

FIGURA 1
Evolução da tecnologia da informação e comunicação nas organizações

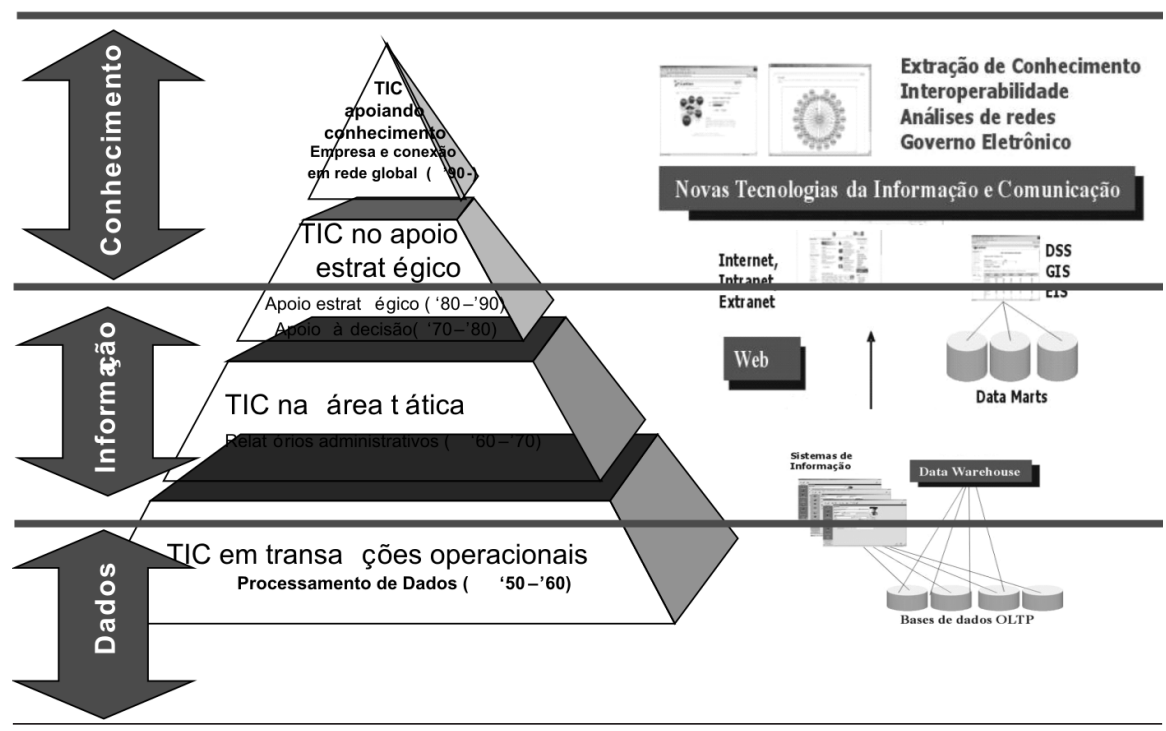

Fonte: adaptada com base em Martin (1982), Martin e Leben (1989) e Pacheco e Kern (2003)

\section{TABELA 1}

Evolução dos Sistemas de Informação

\begin{tabular}{c|c}
\hline Período / Uso & Funções dos Sistemas de Informação \\
\hline De 1950 a 1960 ('50-'60): Processamento de dados & Sistemas de processamento eletrônico de dados: processamento de transações,
\end{tabular}

De 1950 a 1960 ('50-'60): Processamento de dados

De 1960 a 1970 ('60-'70): Relatórios administrativos

De 1970 a 1980 ('70-'80): Apoio à decisão

De 1980 a 1990 ('80-'90): Apoio estratégico e ao usuário final

A partir de 1990 ('90-): Empresa e conexão em rede global

Fonte: adaptado de O'Brien (2004). usuários finais e a gestores das organizações. Na tabela 1, são apresentadas as principais funções desses sistemas nos três marcos fundamentais de sua evolução, como suporte operacional e transformacional de dados, informação e conhecimento. manutenção de registros e aplicações contábeis tradicionais.

Sistemas de informação gerencial: relatórios administrativos de informações pré-estipuladas para apoiar a tomada de decisão.

Sistemas de Apoio à Decisão (SAD): apoio interativo e ad hoc ao processo de tomada de decisão gerencial.

Sistemas de computação do usuário final: apoio direto à computação para produtividade do usuário final e colaboração de grupos de trabalho. Sistemas de suporte a executivos: informações críticas para a alta gerência. Sistemas especialistas: conselho especializado baseado em conhecimento para os usuários finais. Sistemas de informação estratégica. Produtos e serviços estratégicos para obtenção de vantagem competitiva.

Sistemas de informação interconectados: sistemas direcionados ao usuário final, à empresa e à computação, às comunicações e à colaboração interorganizacionais, incluindo operações e administração globais nas Internet, intranets, extranets e outras redes empresariais e mundiais. 
Vê-se ainda, pela figura 1, que cada fase de operação desses sistemas tem o apoio de outras estruturas ou ferramentas essenciais para a eficiência e eficácia de suas funções. Dessa forma, encontram-se os armazéns de dados (Data warehouse) com as bases de dados OLTP (Online Transaction Processing) ou transação de processos on-line, por exemplo, possibilitando a operação dos dados, além de favorecer sua transformação em informações úteis às organizações e transmissão aos ambientes organizacionais, por exemplo. Do mesmo modo, a Web, as extranets e os chamados entrepostos ou subarmazéns de dados (Data marts) somam-se, apoiando os sistemas de informação na tomada de decisões, além de apoiar a transformação das informações em conhecimento. Identicamente, os sistemas interconectados, como sistemas de informações empresariais (Enterprise Information System - EIS), sistemas de informações geográficas (Geographic Information System - GIS) e o padrão de assinatura digital (Standard of digital signature DSS), a Internet, as intranets e outras aparecem como ferramentas de apoio estratégico ao conhecimento. Nessa mesma linha, "novas tecnologias de informação e comunicação" têm surgido, como forma de "extração do conhecimento" explícito, "interoperabilidade" (principalmente como sistemas abertos, habilidade de intercambiar e transmitir dados, informações e conhecimento, uniformidade na interação com o usuário e a construção de interfaces customizáveis), "análise de redes", "governo eletrônico" e tantas outras.

A exemplo dessa pequena amostra de evolução da tecnologia da informação e comunicação, cresce exponencialmente o número das chamadas "ferramentas de gestão do conhecimento", como: APIs - Aplicativos de Interfaces Padronizadas; BI - Business Intelligence; COINS - Communities of Interests Networks (Redes de Interesses de Comunidades); CRM - Customer Relationship Management; CSCW - Computer Supported Cooperative Work (Trabalhos colaborativos apoiados por computador); EIPs - Enterprise Information Portals; EISs - Executive Information System; ERP - Enterprise Resources Planning; ETD - Engagement Team Database (Banco de dados de comprometimento de grupos); GED Gerenciamento de documentos; PdCCs - Portais de conhecimentos corporativos; SGC - Sistemas de Gestão de Conteúdos; Forecasting e Technology Assessment, entre tantas outras.

Observa-se, pois, que há incessante busca pela tecnologia como instrumento de extração do conhecimento humano; de incorporação desse conhecimento, tanto na cultura quanto nos processos de gestão organizacionais e até como forma de gestão do conhecimento (GC). Embora se trate de excelente recurso e valioso suporte à GC, convém lembrar que só a tecnologia não é suficiente. A GC vai além da simples utilização de ferramentas de TI, deve ocupar-se de outros fatores intrinsecamente ligados a características humanas, muitas das quais impenetráveis pela tecnologia, apesar de ainda pouco exploradas. Essa busca acirrada decorre, provavelmente, do fato de que tanto o conceito de TI, quanto a sua realidade nas organizações antecedem ao conceito e à realidade da GC, como meio para gerenciar esses recursos que envolvem principalmente pessoas e tecnologias. Enquanto a tecnologia da informação e comunicação começou a ser utilizada pelas organizações na década de 1950 (figura 1), o conceito de GC, segundo Sveiby (2003, p.3), surgiu no início da década de 1990 , a partir de cujo período, segundo o autor, "a gestão do conhecimento não é mais uma moda de eficiência operacional. Faz parte da estratégia empresarial". Sob a ótica da economia do conhecimento, em contraposição à economia industrial, por exemplo, surge a preocupação com a gestão desse novo capital - o conhecimento.

O objetivo deste artigo é apresentar uma discussão sobre a interação entre tecnologia da informação e gestão do conhecimento como instrumentos de gestão estratégica nas organizações.

\section{REVISÃO DA LITERATURA}

Segundo vários autores, entre os quais Toumi (2001), o sucesso do negócio está ficando cada vez mais dependente da inovação e do conhecimento, que estão mudando as formas tradicionais de organizar negócios nas empresas. As suposições tradicionais em coordenação, controle e apropriação de recursos estão perdendo sua relevância, e as habituais formas de administrar as organizações estão se tornando inadequadas. Com o advento da TI, novas formas de rede de organização estão emergindo e a importância de redes informais dentro e entre organizações está se tornando amplamente concebida. $\mathrm{Na}$ rede da sociedade de conhecimento, as empresas de negócios terão novos experts, e os gerentes de negócio precisam entender de diferentes sistemas de valor. Isto tem implicações no design organizacional, na estratégia, nas práticas de gestão e tecnologias organizacionais, conduzindo às novas teorias e práticas de GC. Como os negócios empresariais têm um papel fundamental no sistema socioeconômico global, é importante entender como o conhecimento está influenciando a mudança desses negócios. Esse entendimento propiciará o desenvolvimento de uma compreensão do sucesso das 
organizações de conhecimento-intensivo e do investimento requerido para esse sucesso.

Para Toumi (2001), novas informações, comunicação e tecnologias computacionais estão mudando fundamentalmente a organização e o conteúdo de trabalho, enfatizando que pelo menos para alguns membros da sociedade, carreiras de trabalho de longavida estão se transformando em um mosaico onde trabalho produtivo, aprendizado e desenvolvimento de competência são inseparáveis.

Diante desse quadro, a integração entre GC e TI aparece como um imperativo para atender a tais necessidades. Essa integração, contudo, é extremamente complexa, pois envolve tanto o gerenciamento de ativos intangíveis de diferentes naturezas - pessoas, conhecimentos tácitos, explícitos, individuais, organizacionais e de redes -, quanto conhecimentos estruturais, que servem de base tecnológica para a estocagem, para a melhoria e para o fluxo dos bens intangíveis, e sistemas de informação com aplicativos que possibilitem o aumento da interação entre pessoas nos ambientes interno e externo, agregando fornecedores e clientes à cadeia de valor das organizações. Diante dessa complexidade, há muitos pesquisadores, como Santiago Júnior (2004), por exemplo, a enfatizar que as TI têm-se tornado o centro nervoso das empresas, um fator estratégico de competitividade e de sobrevivência. Embora isso seja verdade, é preciso cautela, para que não se cometa o equívoco de achar que a TI, em si, seja a solução para o sucesso das organizações. Aliás, Davenport e Prusak (1998) afirmam que algumas organizações, equivocadamente, presumiram que a tecnologia poderia substituir a qualificação e o julgamento de um trabalhador humano experiente, o que se tem revelado falso. Esses autores destacam que a informação se movimenta pelas organizações por redes hard e soft. As redes hard têm uma infra-estrutura definida, formada por fios, utilitários de entrega, antenas parabólicas, centrais de correio, endereços, caixas postais eletrônicas. Envolvem conhecimento estruturado, qualificações técnicas e experiência profissional. Já as redes soft são menos formais e visíveis; são circunstanciais; envolvem um claro senso dos aspectos culturais, políticos e pessoais do conhecimento, da transferência do conhecimento. A integração adequada entre ambas é que permite o bom posicionamento da empresa no mercado, sua resposta acertada às demandas.

Para Davenport e Prusak (1998), o objetivo das ferramentas de GC é modelar parte do conhecimento que existe nas cabeças das pessoas e nos documentos corporativos, disponibilizando-a para toda a organização. A mera existência de conhecimento na empresa é de pouco valor, se ele não estiver acessível e não for utilizado como um dos seus recursos mais importantes. Com essas ferramentas, pretende-se que o conhecimento possa fluir por meio de redes de comunidades, transformando a tecnologia em um meio e o conhecimento em um capital, em uma mensagem.

A expressão gestão do conhecimento assume significados diversos, de acordo com o contexto em que se aplica. Especialmente com o advento da TI e com o avanço nas práticas de gestão organizacional, a GC tem sido entendida sob a forma de diferentes estratégias, a partir das quais as organizações lidam com o conhecimento, interna e externamente, para obter vantagens competitivas. Tal é a constatação de renomados autores na área, como Davenport et al. (1996), por exemplo.

Sveiby (2003) apresenta a seguinte classificação para abordar o campo da GC, tanto em termos das áreas do conhecimento, que a compõem, quanto em relação aos níveis de percepção, que caracterizam o processo:

\section{ÁREAS DO CONHECIMENTO:}

- gestão de pessoas: envolve as áreas de filosofia, psicologia, sociologia e administração, para o entendimento da dinâmica dos processos de criação e difusão de conhecimento tácito;

- gestão da informação: envolve as áreas de tecnologia e ciência da informação, para a construção da base de conhecimento codificado.

\section{NÍVEIS DE PERCEPÇÃO:}

- perspectiva individual: inclui as motivações e as capacidades dos indivíduos;

- perspectiva organizacional: inclui os recursos e as competências essenciais das organizações.

Dessa forma, como afirmam Davenport e Prusak (1998, p.130), "a gestão do conhecimento deve ser parte do trabalho de cada um dos membros da empresa". GC é, pois, a gestão dos ativos intangíveis baseada, sobretudo, na competência dos colaboradores de uma determinada organização.

A GC pode ser sintetizada, segundo Salim (2001), como um processo articulado e intencional, destinado a sustentar ou a promover o desempenho global de uma 
organização, tendo como base a criação e a circulação de conhecimento.

Há forte tendência em correlacionar GC com desempenho organizacional em sentido amplo, o que tem sido comprovado em diversas pesquisas realizadas com métodos diferentes, junto a empresas de distintos perfis e portes, também em locais diferentes. Três estudos recentes a esse respeito feitos por amostragem quantitativamente significativa, detalhando as relações entre GC e desempenho organizacional, apontam-nas como positivas, mas identificam questões intrigantes do ponto de vista da percepção e da forma de inserção da GC no interior das empresas.

O primeiro desses estudos, conduzido por Maier e Remus (2002), descreve o modo como empresas alemãs utilizam a GC. O trabalho foi baseado em uma pesquisa empírica realizada por um dos autores (MAIER, 2002) e em uma pesquisa bibliográfica sobre quatro estudos empíricos de outros pesquisadores sobre o assunto.

No primeiro caso, Maier (2002) investigou o estado-daarte dos sistemas de gestão do conhecimento (Kenowledge Management System - KMS) utilizados nas 500 maiores firmas da Alemanha e nas 50 mais importantes companhias dos setores bancário e de seguros daquele país. Dos questionários enviados, houve retorno de 73 respondentes. Analisando as respostas, Maier e Remus (2002) concluíram que a GC, embora pareça absorver todos os tipos de abordagens teórica e prática, muitas vezes não leva em consideração o valor estratégico ou de negócios. Para eles, a noção de GC está relacionada à alavancagem de recursos que devem ser concentrados em poucas metas, mas claramente definidas. Consideraram, também, GC como a acumulação de recursos pela mineração de experiências e pelo acesso de recursos de outras firmas, de modo que a empresa possa aumentar a velocidade de desenvolvimento de novos produtos, ampliando o seu ciclo de vida. Maier e Remus (2002, p.104) concluíram que "os esforços de GC das organizações respondentes, em média, ainda têm elementos para ir até os mais avançados benefícios que podem ser colhidos".

No segundo caso, a partir da análise dos quatro estudos empíricos de outros pesquisadores, alguns dos quais, estudos de casos, provenientes de dados empíricos, Maier e Remus (2002) elaboraram um quadro das dimensões de estratégias de GC orientadas por processos. Narram o quanto as organizações seguem tais metas de GC e explicam até que ponto elas atingiram essas metas. Mencionam, além disso, que as organizações não dão muita atenção ao valor estratégico de suas iniciativas, ligando GC a atividades estratégicas de negócios ou vantagens competitivas. Os resultados permitiram concluir, finalmente, segundo Maier e Remus (2002, p.105), que “(...) GC, na prática, parece ser um esforço que compreende todos os tipos de atividades, medidas e tecnologias". Para os autores, as estratégias de GC são afetadas pelo uso de tecnologias de informação e comunicação que influenciam todos os níveis de intervenção, isto é, a cultura corporativa subjacente, a estrutura organizational, as funções e processos, classificados como tecnologias que suportam a GC. Na opinião dos autores, isso permite inferir que as tecnologias de informação utilizadas são, de alguma forma, a partir de certas instâncias, confundidas com estratégias de GC ou que estas estratégias têm dimensão secundária como ações integrativas em um sistema de GC. Acrescentam que se pode também atribuir os valores da dimensão secundária ao mecanismo social para troca de conhecimento (ambiente da dimensão cultural).

O segundo estudo, realizado por Leite (2004), analisou as relações entre GC e estratégia; GC e gestão de competências e GC e resultados, em 99 empresas brasileiras a partir de um amplo referencial teórico. Entre os 16 conceitos de GC revisados pela autora, a maioria traduz a expressão como processos, fluxos ou redes de valor, para que as empresas possam chegar a uma posição superior em relação à concorrência. Ela adotou o conceito de Weggeman (1997), que considera GC como um processo contínuo, relacionado à criação de valor em uma cadeia de produção, o que, segundo este autor, confere-lhe dinamicidade.

Entre as principais conclusões, a autora destaca que em muitas organizações as iniciativas para a GC parecem iniciativas isoladas de áreas funcionais, não sendo raro observar esforços de departamentos de recursos humanos ou de tecnologia da informação tentando desenvolver ou implementar projetos de GC, ou seja, a cúpula da maior parte das empresas ainda não apóia as iniciativas de GC, nem tampouco os empregados compreendem o que significa GC. Acrescenta ainda que a potencial contribuição da TI não chega a ser um destaque, restringese ao desenvolvimento e uso dos registros dos ativos intelectuais e dos sistemas de processamento. Leite (2004, f.137) concluiu que "(...) as empresas brasileiras ainda possuem poucas práticas que relacionam a gestão do conhecimento à estratégia empresarial, gestão de competências e de resultado ...”. Inferiu, além disso, que essas empresas não enfrentam os obstáculos que se impõem à implementação da GC. 
O terceiro estudo foi efetuado por McKeen et al. (2006), com objetivo de verificar até que ponto as organizações acoplam, em particular, práticas de GC positivamente relacionadas com desempenho organizacional e se desempenho organizacional é, em troca, positivamente relacionado a desempenho financeiro. Os autores afirmam que estavam pouco interessados nos mecanismos tecnológicos, socioculturais ou estruturais pelos quais a GC é apoiada ou aumentada. Ao invés disso, focalizaram na qualidade e na extensão percebidas nas praticas da GC e como estas práticas se relacionaram a resultados. Dessa forma, o estudo de McKeen et al. (2006) delineia-se como um dos mais exaustivos e completos realizados recentemente sobre o assunto. Os autores elaboraram um quadro com 12 práticas de GC, a partir de 30 pesquisas anteriores, que também relacionaram GC com desempenho organizacional. Pode-se afirmar, portanto, que a base conceitual dos autores está assentada em uma revisão bibliográfica que permite identificar, com expressivo grau de profundidade, os problemas associados à implantação das estratégias de GC. Essas 30 pesquisas, objeto do estudo, foram feitas, respectivamente, uma em 1999, cinco em 2000, quatro em 2001, quatro em 2002, sete em 2003, oito em 2004 e uma em 2005. Com base nesse conjunto de 12 práticas de GC e nos três indicadores de performance organizacional, mencionados como disciplinas de valor por Treacy e Wiersema (1995) liderança em produto, proximidade do consumidor e excelência operacional -, McKeen et al. (2006) elaboraram um questionário para estudar as relações entre GC e desempenho organizacional, em empresas do Canadá e dos Estados Unidos. Apesar de a taxa de retorno à amostra composta de 90 empresas ter sido de apenas 7\%, os autores consideraram válidos os resultados obtidos. Com base nesses resultados, concluíram que a GC deixou de ser um conceito emergente para tornar-se uma função comum nas organizações. Mesmo assim, indicam que na prática ainda há problemas a resolver. Mencionam, nesse sentido, que a cultura talvez seja o fator mais influente na promoção ou inibição de práticas de GC.

Os autores confirmaram o vínculo entre GC e desempenho organizacional, já referido por pesquisas quantitativas e qualitativas, e certa relação positiva, ainda que fraca, entre desempenho organizacional e desempenho financeiro. Suas conclusões são sintetizadas com o seguinte relato:

Mais especificamente, concluímos que as práticas de GC estão diretamente relacionadas a várias medidas intermediárias de desempenho organizacional estratégico (proximidade do consumidor, liderança em produto e excelência operacional) e que essas medidas intermediárias estão associadas ao desempenho financeiro (McKEEN et al., 2006, p.1-2).

Os autores mencionam ainda, com base na pesquisa bibliográfica realizada, que há uma espécie de desequilíbrio entre o desenvolvimento de pesquisas teóricas nessa área e a falta de estudos empíricos que comprovem ou não as hipóteses acadêmicas.

\section{RESULTADOS E DISCUSSÃO}

Apesar das diferenças metodológicas, uma questão que permeia as três pesquisas recentes, mencionadas e sintetizadas na tabela 2, a seguir, sobre GC e desempenho organizacional, diz respeito à visão dos processos em relação à GC. Leite (2004) deixa claro, em seu trabalho, que muitos autores, de certa forma, confundem orientação por processos e melhoria nessa orientação com GC, algo que merece análise mais detalhada.

Confrontando-se não apenas os resultados, mas principalmente as observações propostas em cada uma dessas pesquisas, conclui-se pela ausência de uma percepção, por parte das empresas-alvo dos estudos, que relacione os conhecimentos gerados nos processos de negócios com aqueles que surgem e se desenvolvem ao longo das estruturas verticais das organizações, as quais dão suporte e infra-estrutura à realização dos processos. Assim como existe tendência a considerarem-se todos os fluxos como processos, independentemente de gerarem ou não valor, há falta de percepção referente à articulação dos conhecimentos gerados nas estruturas verticais (funcionais) e horizontais (processuais) e com respeito à estrutura-síntese que possibilitaria que essa articulação fosse caracterizada como gestão. Não existe, portanto, uma visão integradora de processos a estruturas funcionais e vice-versa, e de como o conhecimento gerado nesse complexo de interações poderia ser gerenciado. Se falta uma concepção de GC como estratégia, segundo afirmam Maier e Remus (2002) e Leite (2004), e se a GC tende a incorporar-se como função, conforme afirmam McKeen et al. (2006), resta compreender se a função da GC seria estratégica, ou seja, integradora dos processos horizontais e verticais, em um plano superior da gestão.

Embora sejam recentes os estudos sobre GC, o número de pesquisas tem crescido bastante, em uma nítida evidência da importância dessa área. Nota-se, contudo, que as organizações ainda não têm uma visão clara de como incorporá-la em sua cultura, de modo a transformá- 
TABELA 2

Conceitos de GC e suas respectivas características, segundo as organizações objeto dos três principais estudos abordados

\begin{tabular}{|c|c|c|c|}
\hline Autores & $\mathrm{O}$ que estudaram & Conceitos de GC & Conclusão \\
\hline Maier e Remus (2002) & $\begin{array}{l}\text { Investigaram o estado-da-arte da } \\
\text { GC nas } 500 \text { maiores firmas da } \\
\text { Alemanha e nas } 50 \text { mais importantes } \\
\text { companhias dos setores bancário e } \\
\text { de seguros daquele país. }\end{array}$ & $\begin{array}{l}\text { A GC está relacionada à } \\
\text { alavancagem de recursos, os } \\
\text { quais devem ser concentrados } \\
\text { em poucas metas. E também à } \\
\text { acumulação de recursos pela } \\
\text { mineração de experiências e } \\
\text { pelo acesso aos recursos de } \\
\text { outras firmas, de modo que a } \\
\text { empresa possa aumentar a } \\
\text { velocidade do desenvolvimento } \\
\text { de novos produtos, acelerando } \\
\text { o seu ciclo de vida. }\end{array}$ & $\begin{array}{l}\text { "(...) GC, na prática, parece ser } \\
\text { um esforço que compreende } \\
\text { todos os tipos de atividades, } \\
\text { medidas e tecnologias"."Os } \\
\text { esforços de GC das empresas } \\
\text { respondentes, em média, ainda } \\
\text { têm elementos para colher } \\
\text { benefícios mais avançados". }\end{array}$ \\
\hline McKeen et al. (2006) & $\begin{array}{l}\text { Estudaram as relações entre GC e } \\
\text { desempenho em } 90 \text { empresas do } \\
\text { Canadá e dos Estados Unidos. } \\
\text { A partir daí, elaboraram um quadro } \\
\text { com } 12 \text { práticas de GC, a partir de } \\
30 \text { pesquisas anteriores, as quais } \\
\text { também relacionaram GC com } \\
\text { desempenho organizacional. }\end{array}$ & $\begin{array}{l}\text { A base conceitual dos autores, } \\
\text { portanto, está assentada em uma } \\
\text { revisão bibliográfica que } \\
\text { permite identificar com } \\
\text { expressivo grau de profundidade } \\
\text { os problemas associados à } \\
\text { implantação das estratégias de } \\
\text { GC. }\end{array}$ & $\begin{array}{l}\text { "A GC deixou de ser um } \\
\text { conceito emergente para tornar- } \\
\text { se uma função comum nas } \\
\text { organizações"."Confirmaram a } \\
\text { existência de vínculo entre GC } \\
\text { e desempenho, já referido em } \\
\text { outras pesquisas". }\end{array}$ \\
\hline
\end{tabular}

la em grande fator de sucesso. Em contrapartida, é escassa a literatura que aborde especificamente a função da TI na GC. Provavelmente dessa lacuna, decorre a falta de clara distinção entre TI e GC, de modo que a interação adequada entre ambas aumente substancialmente o desempenho organizacional, permitindo às empresas posição de destaque no mercado. Em nenhuma das pesquisas referidas, há menção evidente do papel das TI nos sistemas de GC utilizados nas organizações estudadas. Com exceção de McKeen et al. (2006), que esclarecem que seus objetivos não visavam a mecanismos tecnológicos, os outros se restringem a afirmações genéricas. Maier e Remus (2002) relatam que as práticas de GC compreendem as tecnologias, que as estratégias de GC são afetadas pelas tecnologias de informação e comunicação, embora não digam como afetam; e que as TI, de certa forma, são confundidas com GC. Leite (2004), por sua vez, limita-se a dizer que há organizações que confundem GC com TI e que a contribuição desta, nas empresas estudadas pela autora, não chega a ser um destaque.
As pesquisas de Maier e Remus (2002), Leite (2004) e McKeen et al. (2006) apontam diversos tipos de lapsos entre o que as empresas consideram GC e seu desempenho organizacional, sob o ponto de vista mais amplo que o de simples processos de negócios.

Para Maier e Remus (2002), o vínculo entre GC e estratégia de negócios não está amplamente implementado na prática, devido à ausência de modelos que relacionem esforços de GC, no sentido de processos orientados por conhecimento, estrutura e instrumentos organizacionais, atividades relativas à cultura empresarial, implementação de tecnologias e estratégia de negócios. Conforme esses autores, essa lacuna seria preenchida com a implementação de uma visão por processos, sendo a GC aplicada tanto em nível interno, quanto às áreas externas da organização, principalmente àquelas que se relacionam ao ambiente competitivo do mercado: consumidores, competidores e acionistas. Eles acreditam que deve haver um equilíbrio entre a visão baseada em recursos defendida por alguns autores e a 
visão baseada em mercado, no plano das vantagens competitivas. Nesse contexto, uma estrutura para estratégias de gestão do conhecimento pode ser baseada na tradicional análise de Oportunidades e Ameaças; Sucessos e Fracassos (Opportunities and Threats; Strengths and Weaknesses - SWOT), proposta por Zack (1999), na qual a estratégia é vista como instrumento de equilíbrio entre as forças dos ambientes externo e interno à organização. No ambiente externo, referente às oportunidades e ameaças e no ambiente interno, referente aos sucessos e fracassos. $\mathrm{O}$ ambiente externo age, empurrado pela estrutura do modelo das cinco forças ou fatores, desenvolvido e proposto por Porter (1998, p.4), conhecidas como "Ameaça da entrada de outras organizações no mercado; Poder de barganha dos fornecedores; Poder de barganha dos compradores; Ameaça da disponibilidade de serviços ou de produtos substitutos; Concorrentes". Esse modelo representa uma estratégia de orientação de mercado que internamente é estudado sob as lentes das capacidades e potencialidades dos recursos básicos existentes na organização. Por isso, acredita-se que o conhecimento é um dos mais importantes, se não o recurso estratégico mais importante de uma organização. Para Maier e Remus (2002, p.116),

a grande vantagem da assim chamada estratégia de GC orientada por processos é que ela possibilita uma integração da visão baseada em recursos e da visão orientada ao mercado da organização.

Um ponto de vista alternativo para solucionar os lapsos entre GC e desempenho seria a adoção de uma perspectiva mais pragmática que, conforme Maier e Remus (2002), não distingue entre estratégias, instrumentos, atividades e esforços, estando unicamente baseadas em pesquisas empíricas. Neste aspecto, esses autores relacionam oito itens que consideram importantes:

- mapeamento de fontes de especialização interna, tornando visíveis os recursos relacionados ao conhecimento;

- estabelecimento de novos papéis de conhecimento, como operadores ou engenheiros de conhecimento;

- criação de ambientes virtuais para permitir o compartilhamento de conhecimento tácito;

- sustentação de fluxos de conhecimento nas organizações, adaptando-se modelos de comunicação a essa necessidade;
- gestão do conhecimento como estratégia de negócios, podendo-se escolher entre integrar a GC a todas as estratégias, ou apenas a algumas consideradas essenciais;

- conhecimento focado no consumidor, capturandose suas necessidades, preferências, reações;

- estratégia de gestão de recursos intelectuais, como patentes, propriedade intelectual, arranjos organizacionais;

- inovação e criação do conhecimento, com pesquisa e desenvolvimento focados na melhoria das inovações (MAIER; REMUS (2002, p.105).

A falta de um terreno fértil, de uma espécie de preparação para que as empresas brasileiras adotem práticas que tipifiquem a relação entre GC e desempenho organizacional, é também constatada por Leite (2004), com a seguinte afirmação:

(...) o fato de as empresas brasileiras não aplicarem estas práticas permite supor que uma das prováveis razões, que faz com que as empresas tenham dificuldade para iniciar ou abandonar projetos dessa natureza, tem origem na falta de uma base solidamente constituída para que compreendam e reconheçam o conhecimento como recurso estratégico, como elemento-chave da construção das competências organizacionais e humanas e como parte a ser avaliada e acompanhada na contribuição do resultado organizacional (LEITE, 2004, f.138).

Portando, se o conhecimento ainda não é visto na organização como recurso estratégico, há de se alcançar este estágio, a partir de uma análise das bases representadas por tais práticas.

Leite (2004) menciona que o conhecimento tácito ainda é pouco trabalhado pelas empresas brasileiras, que têm dificuldade para gerenciá-lo, no tocante ao nível de socialização entre as pessoas. Ressalta, porém, que aquelas que valorizam tanto o conhecimento tácito quanto o explícito conseguem melhor desempenho. Segundo a autora, quase a metade confunde TI com GC e 49\% das 99 empresas ouvidas acreditam que a TI possa sozinha servir para gerenciar o conhecimento. Observou, contudo, que os entraves detectados na GC tácito apontam o inverso, ou seja, que a supremacia da TI é algo ilusório se não existe o desenvolvimento correspondente na área do inter-relacionamento humano. Outro lapso verificado é a falta de transparência quanto à divulgação 
dos propósitos mais elevados da administração. Dentre as empresas respondentes, apenas $8 \%$ afirmaram que deixam clara a sua estratégia organizacional para empregados de todos os níveis. Já o conceito de competência como resultado de conhecimentos, habilidades, atitudes e resultados alcançados por um indivíduo no seu trabalho é aplicado por $20 \%$ das empresas respondentes. A GC como processo contínuo, envolvendo ações que determinam os conhecimentos de acordo com a estratégia, a identificação de conhecimentos disponíveis, o compartilhamento, a aplicação e a avaliação do valor do conhecimento para o negócio, é um conceito aplicado por somente 5\% das empresas entrevistadas. Além disso, 14\% delas possuem métricas para GC, 8\% têm equipes específicas para ações de GC e $9 \%$ possuem orçamento para essa área. Ficou evidenciado, também, que, nas organizações brasileiras, o estilo dinâmico, que qualifica as empresas que enfatizam simultaneamente os níveis tácito e explícito do conhecimento, tem relação com o desempenho superior apresentado por essas empresas.

McKeen et al. (2006) chamam a atenção ao fato de que as organizações avaliam diferentemente as práticas de GC quando tomadas isoladamente e quando combinadas com disciplinas de desempenho organizacional, liderança em produto, proximidade do consumidor e excelência operacional. McKeen et al. (2006, p.1) afirmam ser "surpreendente a existência de um lapso significativo entre as práticas de GC que as firmas acreditam ser importantes e aquelas que estão diretamente relacionadas ao desempenho organizacional”. Na avaliação dos pesquisadores, isto talvez seja um indício da falta de uma evidência empírica de grande escala, que possibilite assegurar que a GC faz mesmo diferença para o desempenho organizacional. Eles ressaltam que, no tocante aos impactos na GC, os resultados financeiros e não financeiros são construtos diferentes, ou seja, se houver mudanças nas práticas de GC, elas não necessariamente afetarão o desempenho financeiro.

Um fator de restrição ou de estímulo à GC, dependendo de como seja moldado, é a cultura organizacional. Para McKeen et al. (2006), organizações que valorizam seus empregados pelo que eles sabem e que os recompensam por compartilhar seus conhecimentos criam um clima mais favorável à GC. A ausência de ações desse tipo pode inibir a GC e dificultar o desempenho organizacional.

Os estudos relacionando GC a desempenho organizacional, embora recentes, têm apresentando uma tendência de crescimento significativo nos últimos três anos. Contudo, os pesquisadores ainda encontram dificuldades para estabelecer indicadores que correlacionem efetivamente a GC com os aspectos do desempenho organizacional.

McKeen et al. (2006), após uma exaustiva revisão de pesquisas sobre as relações entre GC e desempenho organizacional, concluíram que existem 12 indicadores de práticas de GC que podem ser associados a práticas voltadas à competitividade externa, como liderança em produto, intimidade com o consumidor e excelência operacional. Eles ressaltam que algumas práticas de GC consideradas relevantes por seus entrevistados do Canadá e dos Estados Unidos, para efeito do desempenho organizacional, foram avaliadas diferentemente quando tomadas individualmente e quando cruzadas com as práticas mencionadas de desempenho externo.

A GC é, por assim dizer, a capacidade de lidar de forma criativa com as diferentes dimensões do conhecimento, desde sua criação a partir de dados, sua transformação em informações, e, a partir da análise das informações e sua transformação em conhecimento propriamente, sua contextualização, categorização, armazenamento, uso e disseminação, correção, compilação e reutilização. Para Kruglianskas e Terra (2003), a gestão do conhecimento aumenta e complementa outras iniciativas organizacionais, tais como o gerenciamento total da qualidade, a reengenharia de processos e o aprendizado organizacional, proporcionando novo e urgente centro de atenção para sustentar a posição competitiva. Assim, pode-se concluir que a GC está intimamente relacionada ao fator sucesso na tomada de decisões, o qual tende a aumentar à medida que aumenta a interação entre GC e TI. As ferramentas de GC pretendem auxiliar no processo de captura e estruturação do conhecimento de grupos de indivíduos, disponibilizando esse conhecimento em uma base compartilhada (base de conhecimento) por toda a organização.

GC, portanto, não é só tecnologia, envolve, além disso, gestão de pessoas, com perspectivas e motivações individuais, aspectos psicológicos, emocionais e valores intrínsecos de personalidade e caráter. Administrar esse recurso pressupõe a prática constante e ininterrupta dos quatro pilares do conhecimento, preconizados por Delors (2001): aprender a conhecer; aprender a fazer; aprender a viver juntos (aprender a viver com os outros); aprender a ser. Para isso, embora seja necessário dispor de bons indicadores de desempenho, mas não é suficiente. É indispensável criar ambiente favorável ao compartilhamento, não só do conhecimento inerente 
aos aspectos organizacionais, mas também daquele referente aos requisitos e valores humanos, que podem favorecer a internalização e a codificação do conhecimento tácito, que não é tão simples, portanto precisa ser objeto de cuidado pelas empresas, a fim de ser explorado e valorizado convenientemente.

Amaratunga et al. (2002), ao referirem-se às constantes mudanças no mundo dos negócios e classificá-las como geradoras de incertezas no interior das organizações, recomendam a implantação de ferramentas como o BSC - Balanced scorecard -, por exemplo, como forma de equilibrar e preservar a organização de certos riscos. Os autores enumeram, além disso, outras vantagens dessa ferramenta como apoio a um modelo de gestão, tais como ajudar a agilizar e manter a comunicação em todos os níveis, possibilitar o desenvolvimento de metas organizacionais, favorecer a criação de um sistema de recompensa e reconhecimento para a melhoria do desempenho futuro, permitir a quebra de barreiras organizacionais, apoiar a coordenação de possibilidades de crescimento, demonstrar a necessidade de melhorias de forma clara, oportunizar uma tentativa inicial realista de implementação, integrar o sistema de medida de desempenho da organização e facilitar a mudança de cultura corporativa.

Os resultados obtidos nos principais estudos, que estão resumidos na tabela 2, permitem concluir que a GC deve ser vista ao mesmo tempo como brotando da melhoria dos processos e como suportada pelos arranjos organizacionais funcionais. Contudo, é importante a realização de pesquisas empíricas, capazes de esclarecer como os processos geradores de conhecimento, ao nível horizontal, podem integrar-se ao conhecimento gerado verticalmente, de modo que a GC seja exercida sem que se abra mão da estratégia. Tal complexidade merece novas pesquisas, embora não seja assunto novo. Em 1976, o general Clausewitz, famoso estrategista de guerra, segundo Mukherji e Mukherji (2003, p.1), já reconhecia que "tudo em estratégia é muito simples, mas isto não significa que tudo seja muito fácil".

O papel principal da TI na GC consiste em dar suporte à gestão do conhecimento, em ampliar o alcance e acelerar a velocidade de transferência do conhecimento. É importante ressaltar que a TI desempenha um papel de infra-estrutura, pois a GC envolve também aspectos humanos e gerenciais. Sua função é identificar e/ou desenvolver e implantar tecnologias e sistemas de informação que dêem apoio à comunicação empresarial e à troca de idéias e experiências. Isso facilita e incentiva as pessoas a se unirem, a tomarem parte de grupos. Favorece a renovação em redes informais de aquisição e troca de conhecimento, além de facilitar o compartilhamento de problemas, perspectivas, idéias e soluções em seu dia-a-dia profissional.

Nota-se, embora que timidamente, esforços que apontam para a efetividade da GC e, nesse contexto, a função da TI e seus serviços como meios para o sucesso de uma estratégia, e não como um fim em si mesmo. É evidente, também, a necessidade de alinhamento da tecnologia com os processos da empresa e com as questões relativas à interação entre as pessoas, certamente o recurso intangível mais importante em todo esse contexto. Esta temática é algo que precisa ser igualmente aprofundada.

\section{CONCLUSÕES}

O resultado do estudo, a pesquisa bibliográfica e elaboração do trabalho permitiram as seguintes conclusões:

1. A importância da GC é percebida pelo aumento de pesquisas sobre o assunto. Há, contudo, um desequilíbrio entre pesquisas teóricas e empíricas que comprovem as hipóteses acadêmicas e mostrem que a GC faz diferença no desempenho organizacional. Parece faltar uma sólida base conceitual que abranja a organização, proporcionando, a todos os colaboradores, clara compreensão do que significa GC. Provavelmente por isso, muitas delas ainda não têm uma visão clara de como incorporá-la em sua cultura, de modo a transformá-la em grande fator de sucesso. A cultura talvez seja o fator mais influente na promoção ou inibição de práticas de GC.

2. O conhecimento tácito ainda não aparenta ser tão creditado pelas organizações, quanto o explícito. Parece haver dificuldade para geri-lo no âmbito da socialização entre as pessoas. Organizações que valorizam seus empregados pelo que eles sabem, recompensando-os por compartilhar seus conhecimentos, criam um clima mais favorável à GC e conseguem melhor desempenho.

3. Apesar de alguns obstáculos que impedem melhor entendimento da função da GC, já existe grande número de iniciativas de GC em andamento nas organizações. Elas combinam várias abordagens, atividades singulares diferentes e tecnologias, que supostamente entregam valores de negócios, pela melhoria do modo como as organizações alavancam o conhecimento. 
4. A GC está intimamente relacionada ao fator sucesso na tomada de decisões, o qual tende a aumentar à medida que aumenta a interação entre GC e TI. Essa interação apropriada é que permite o bom posicionamento da empresa no mercado, sua resposta acertada às demandas.

5. Os gestores devem atentar ao contexto da estratégia organizacional, focando-a na obtenção de melhoria do desempenho organizacional, a partir de uma visão integrada de GC, tanto nos planos vertical (das estruturas funcionais e de comando), quanto horizontal (relativo aos processos), pela busca do alinhamento entre práticas de GC e outras disciplinas voltadas à agregação de valor.

6. É escassa a literatura que aborde especificamente a função da TI na GC. Provavelmente dessa lacuna, decorre a falta de clara distinção entre TI e GC e o fato de certas organizações confundirem tecnologias de informação com estratégias de GC. Isso parece obstaculizar, de certa forma, a adequada interação entre ambas, o que propiciaria substancial aumento do desempenho organizacional.

7. Há empresas que acreditam que adquirir e implantar ferramentas e processos baseados apenas na tecnologia da informação seria suficiente para qualificá-las como uma empresa orientada para a gestão do conhecimento, o que significa, no mínimo, um grande equívoco.

8. A TI desempenha um papel de infra-estrutura na GC. É utilizada como ferramenta de apoio à análise de mercado e suporte à tomada e decisão. Funciona como instrumento para desenvolver e implantar tecnologias que apóiem o mapeamento, a extração, a codificação, a modelagem, a disponibilização, o compartilhamento do conhecimento e a comunicação empresarial. Favorece a interação entre pessoas e grupos (gestores, operadores do conhecimento e empregados). A mera existência de conhecimento na empresa é de pouco valor, se ele não estiver acessível e não for utilizado como um dos seus recursos mais importantes.

9. A TI é um instrumento facilitador da rápida mobilidade do conhecimento no interior das organizações. Um fator estratégico de competitividade e de sobrevivência nas empresas. É preciso, porém, cautela para que não se cometa o equívoco de julgar que a TI, em si, seja a solução para o sucesso das organizações.

10. O grande desafio da GC parece ser: Como gerenciar as chamadas organizações de conhecimento intensivo? Como modelar o conhecimento para transformá-lo em um ativo que implique resultados para as organizações? Como mensurar dimensões de gestão que não podem ser expressas em valores financeiros, mas que fazem grande diferença no desempenho geral das organizações e permitem conquistar e manter uma posição sustentável no mercado? Como GC e TI podem interagir de modo eficaz nesse processo?

Artigo submetido em 02/06/2007 e aceito em 24/10/2007.

\section{REFERÊNCIAS}

AMARATUNGA, Dilanthi et al. Application of the balanced scorecard concept to develop a conceptual framework to measure facilities management performance within NHS facilities. International Journal of Health Care Quality Assurance, v. 15, n. 4, p. 141-151, 2002.

DAVENPORT, Thomas, H.; JARVENPAA, Sirkka, L.; BEERS, Michael, C. Improving knowledge work processes. Sloan Management Review, Cambridge Massachusetts, v. 37, n. 4, p. 53-65. Summer 1996.

; PRUSAK, Laurence. Conhecimento empresarial: como as organizações gerenciam o seu capital intelectual. Trad. de Lenke Peres. 8. ed. Rio de Janeiro: Campus, 1998. 237 p.

DELORS, Jacques. Educação: um tesouro a descobrir: relatório para a Unesco da Comissão Internacional sobre Educação para o século XXI. 5. ed. São Paulo: Cortez; Brasília: UNESCO, 2001. 288 p.

KRUGLIANSKAS, Isak; TERRA, José Cláudio Cyrineu. Gestão do conhecimento em pequenas e médias empresas. São Paulo: Negócios Editora, 2003. 375 p.

LEITE, Eliane Santos. Gestão do conhecimento nas empresas brasileiras: relações entre estratégia empresarial, gestão de competências e de resultado e impactos no desempenho de negócios. 2004. 186 f. Dissertação (Mestrado em Administração de Empresas) - Programa de Pós-graduação, Pontifícia Universidade Católica do Rio de Janeiro, Rio de Janeiro, 2004.

MAIER, Ronald. State-of-practice of knowledge management systems - results of an empirical study. Journal of the Swiss Computer Society, v. 3, n. 1, p. 15-23, Feb. 2002. Informatik/Informatique, Zeitschrift der Schweizerischen Informatikorganisationen. Disponível em: <http:// www.upgrade-cepis.org/issues/2002/1/up3-1Maier.pdf $>$. Acesso em: 30 jan. 2006.

; REMUS, Ulrich. Defining process-oriented knowledge management strategies. Knowledge and Process Management, Hoboken, v. 9, n. 2, p. 103-118, Apr./June 2002.

MARTIN, James. Strategic data-planning methodologies. 2nd ed. Englewood Cliffs, New Jersey: Prentice Hall, 1982. 236 p.

; LEBEN, Joe. Strategic information planning methodologies. 2nd ed. Englewood Cliffs, New Jersey: Prentice-Hall, 1989. 328 p.

MCKEEN, J. D.; ZACK, M. H.; SINGH, Satyendra. Knowledge management and organizational performance: an exploratory survey. In: HAWAII INTERNATIONAL CONFERENCE ON SYSTEM SCIENCES, 39., 2006. Hawaii. Proceedings... Hawaii: [s.n.], 2006.

MUKHERJI, Ananda; MUKHERJI, Jyotsna. Understanding strategy: why is strategy so difficult?. Advanced in Competitiveness Research, v. 11, n. 1, p. 1-19, 2003. 
O'BRIEN, James. A. Sistemas de informação e as decisões gerenciais na era da Internet. Trad. de Célio Knipel Moreira e Cid Knipel Moreira. 2. ed. São Paulo: Saraiva, 2004. 431 p.

PACHECO, Roberto Carlos dos Santos; KERN, Vinicius Medina. Arquitetura conceitual e resultados da integração de sistemas de informação e gestão da ciência e tecnologia. DataGramaZero - Revista de Ciência da Informação, v. 4, n. 2, abr. 2003. Disponível em: < http:// www.dgz.org.br/abr03/Art_03.htm>. Acesso em: 27 set. 2005.

PANT, Somendra; HSU, Cheng. Strategic information systems planning: a review. In: INFORMATION RESOURCES MANAGEMENT ASSOCIATION INTERNATIONAL CONFERENCE., 1995, Atlanta/Georgia. Proceedings .... Atlanta/ Georgia: [s.n.], 1995.

PORTER, Michael. E. Competitive strategy: techniques for analysing industries and competitors. 1. ed. New York: [s.n.], 1998. 396 p.

SALIM, Jean Jacques. Palestra gestão do conhecimento e transformação organizacional. In: SEMANA DA EQ/UFRJ, 68., 2001, Rio de Janeiro. Anais .... Rio de Janeiro: Universidade Federal do Rio de Janeiro, 2001.
SANTIAGO JÚNIOR, José Renato Sátiro. Gestão do conhecimento: a chave para o sucesso empresarial. São Paulo: Novatec, 2004. 208 p.

SCHREIBER, Guus et al. Knowledge engnineering and management: the CommonKADS methodology. Cambridge/Massachussets: MIT Press, $2002.932 \mathrm{p}$.

SVEIBY, Karl Erik. A nova riqueza das organizações: gerenciando e avaliando patrimônios de conhecimento. 7. ed. Rio de Janeiro: Campus, $2003.260 \mathrm{p}$.

TOUMI, Iikka. From periphery to center: emerging research topics on knowledge society. Technology Review, Helsinki, v. 16, p. 1-63, Aug. 2001.

TREACY, Michael; WIERSEMA, Frederik D. A disciplina dos líderes de mercado: escolha seus clientes, direcione seu foco, domine seu mercado. Trad. de Nivaldo Montingelli. Rio de Janeiro: Rocco, 1995. $236 \mathrm{p}$.

WEGGEMAN, Mathieu. Knowledge management. Shiedam: Scriptum, 1997.

ZACK, Michael H. Developing a knowledge strategy. California Management Review, Califórnia, v. 41, n. 3, p. 125-145, 1999. 